${ }^{1}$ Dr. A S M Anwarul Kabir Registrar, Dept. of Surgery Holy Family Red Crescent Medical College (HFRCMC), Dhaka

${ }^{2}$ Prof. Imtiaz Ahmad Professor, Dept. of Surgery HFRCMC, Dhaka

Dr. Mahbuba Sharmin Medical officer

Bangabandhu Sheikh Mujib Medical University, Dhaka

${ }^{4}$ Dr. Khaleda Akhter Registrar

HFRCMC, Dhaka

${ }^{5}$ Dr. Md. Rashidul Hoq Assistant professor

Dept. of Surgery HFRCMC, Dhaka

${ }^{6}$ Dr. Mohammad Shahidul Alam Professor of Botany and Ex-Chairman, Dept. of Physical Education \& Sports Sciences, Rajshahi University

\section{Correspondence}

Dr. A S M Anwarul Kabir HFRCMC, Dhaka

Email: dr.anwar28@gmail.com

\title{
Early outcome of Lichtenstein technique for complete variety of inguinal hernia repair in a tertiary care hospital
}

\author{
A S M A Kabir ${ }^{1}$, I Ahmad ${ }^{2}$, M Sharmin ${ }^{3}$, K Akhter ${ }^{4}$, M R Hoq ${ }^{5}$, M S Alam ${ }^{6}$
}

Abstract

Background : Inguinal hernia repair is very common in day to day general surgical practice. Result of surgical repair is often satisfactory but recurrences following surgery are troublesome both for the surgeon and the patient. Lichtenstein technique is now the most widely performed technique in groin hernia repair.

Objective : The aim of this study was to assess short term outcome of complete variety of inguinal hernia repair by Lichtenstein technique.

Methodology : This was a prospective observational study in which 30 complete variety of inguinal hernia repairs were performed by Lichtenstein technique between January 2014 and December 2017 by same surgical team in surgery department, Holy Family Red Crescent Medical College Hospital (HFRCMCH). Patients were scheduled for follow up visits at the end of first week, third month and sixth month after operation in out-patient department. The main outcome measures were postoperative complications, early recurrence, groin pain.

Result : In this study age of the patients ranged from 30 years to 78 years, the mean age was $51.93( \pm S D 10.12)$ years. Most of the hernia were of indirect type $18(60 \%)$ followed by direct type $9(30 \%)$. In indirect type $(55.6 \%)$ of the hernias was right sided and the rest (44.4\%) were left sided. On an average each operation lasted for 1.18 hours and oral feeding started 12.69 hours after the operation, Postoperative mean hospital stay that was 2.27 days. Postoperative complications were $2(6.7 \%)$ had a prolonged recovery and presented with abdominal distention after operation and $3(10 \%)$ patients developed postoperative urinary retention. Scrotal haematoma formation was observed in $2(6.7 \%)$ cases and other post operative complications were local haematoma or seroma formation in incision site, periincisional skin echymosis, postoperative pyrexia, superficial wound infection and post operative pain were found in 1 $(3.3 \%)$ cases. Regarding outcome no recurrence or mesh rejection or mesh infection were observed within short time postoperative follow up period.

Conclusion : In this study no recurrence or mesh rejection or mesh infection were observed within short time postoperative follow up period and patient's compliance was good with minimum morbidity. Therefore, Lichtenstein's technique of inguinal hernia repair considered as a safe and effective procedure.

Key words : Direct and Indirect inguinal hernia, Lichtenstein's technique, Scrotal haematoma, Mesh rejection.

DOI: https://doi.org/10.3329/nimcj.v10i2.45435

Northern International Medical College Journal Vol. 10 No. 2 January 2019, Page 389-392

\section{Introduction}

Inguinal hernia, regardless of type is one of the most common diseases that a surgeon has to manage and it accounts for around $75 \%$ of all anterior abdominal wall hernias, with a prevalence of $4 \%$ in those over 45 years. ${ }^{1}$ It is estimated that 20 millions of inguinal hernia repairs are performed globally every year. ${ }^{2}$ More than one million hernia repairs are performed each year in the U.S and approximately 800,000 are to repair inguinal hernias. ${ }^{3,4}$

Traditionally almost all inguinal hernias are referred for surgical treatment following diagnosis. Initially patient with inguinal hernia refuse surgical intervention as it is a benign disease. By nature hernia progresses and its content extend into scrotum forming the complete variety. For this reason most surgeons prefer repair of inguinal hernias as soon as possible. $^{5}$

The "tension-free" mesh technique was pioneered by the Lichtenstein Hernia Institute in $1984 .{ }^{3-5}$ Mesh used here is typically made from polypropylene or polyester. ${ }^{2,4}$ Lichtenstein technique is now most widely used method for inguinal hernia repair. It is safe, simple, easy to perform and very effective in prevention of 
recurrences. In this technique, there is comfortable postoperative course with easily controlled pain, rapid return to daily normal activities, an impressively very low acceptable recurrence rate and high patient satisfaction. For all of these reasons this technique is currently considered the gold standard for hernia repair by the American College of Surgeons.

Complications found in this technique are foreign body reaction, haematoma or seroma formation infection, pain, sinus formation, orchitis and testicular atrophy specially in complete variety of inguinal hernia, migration of mesh and recurrence of hernia. ${ }^{5,6}$ Secondary or tertiary repair after previous surgery carry higher risk of re-recurrence and other complications. Every recurrence after a repair will add an extra burden to health care system.

Surgery for complete variety of inguinal hernia is very challenging. ${ }^{7}$ During operation more tissue dissection done in inguino-scrotal region and sometimes hernial sac is removed during surgery. ${ }^{8}$ There is more chance of seroma formation and a drain is required. Therefore, mesh related complications occur. ${ }^{3,5}$ In complete variety sometimes hernial sac is large and large volume of herniated gut or greater omentumare returned back into abdominal cavity. Delay in postoperative recovery may be found due to postoperative abdominal distension and delayed return of normal bowel function.

Till now there is also very few data is available in Bangladesh regarding Lichtenstein procedure in treating complete variety of inguinal hernia. Therefore, in this study we have tried to assess the short term outcome of complete variety of inguinal hernia repair by Lichtenstein technique.

\section{Materials and Methods}

In this prospective observational study 30 patients having complete variety of inguinal hernia were selected aand operations were performed by same surgical team in Surgery department of Holy Family Red Crescent Medical College Hospital, Dhaka during January 2014 to December, 2017.

\section{Inclusion criteria}

- Patients who were clinically diagnosed as a case of complete variety of inguinal hernia

- age more than 18 years

- who willingly gave informed consent to take part in this study

\section{Exclusioncriteria}

- Ageless than18 years

- patients with obstructed hernia, irreducible hernia, strangulated hernia

- patients with other medical diseases e.g.chronic cough, chronic constipation, uncontrolled Diabetes Mellitus, psychiatric problems

- pregnant woman.

All patients were explained about the nature, purpose of study and written informed consents were taken from them. Permission from Ethical Review Board of the institution was also taken.

Preoperative workout : Following admission a detailed history,physical examinationwas performed and relevant investigations were done in all patients to assess fitness for anaesthesia. A day before surgery the patients advised to take clear fluid diet and were nil per orally from midnight before day of surgery. Over night sedation with oral midazolam was given in anxious patients. All operations were done under spinal anaesthesia.

Operative workout : All patients' hernias were repaired according to Lichtenstein technique. A polypropylene mesh (3 $\times 6$ inch) is trimmed to fit the floor of the inguinal canal and its apex is sutured to the public tubercle using a 2-0 polypropylene suture.

Post operative care: Patient was given same analgesics (Pathedine and Ketoralac for 4 days) and antibiotic Cefurexime used preoperatively and continued for next 5 days. Limited mobilization up to 24 hours following surgery was advised.

The follow up schedule was explained to all patients at the time of discharge and schedule for follow up was at the end of $1^{\text {st }}$ week, $3^{\text {rd }}$ and $6^{\text {th }}$ month after operation. During follow up data regarding the development of complications postoperatively and recurrence in follow up period were recorded and evaluated. For analysis of data SPSS (version 17.0) software was used.

\section{Result}

A total number of 30 patients were treated by tension free mesh repair by Lichtenstein technique in the study period. Age of the patients ranged from 30 years to 78 years, the mean age was 51.93 ( \pm SD 10.12 ) years and $70 \%$ of the patients were between 40 to 60 years of age.

\begin{tabular}{|lcc|}
\hline Table I : Age group of the patients & \\
\hline Age group (years) & Frequency & Percent \\
$30-40$ & 5 & 16.7 \\
$41-50$ & 9 & 30.0 \\
$51-60$ & 12 & 40.0 \\
$61-70$ & 2 & 6.7 \\
$>71$ & 2 & 6.7 \\
Total & $\mathbf{3 0}$ & $\mathbf{1 0 0 . 0}$
\end{tabular}

Most of the hernia were of indirect type (18/30) followed by direct type (9/30). Pantaloon variety found only in (3) patients (table II). 
Table II: Types of hernia

\begin{tabular}{lcccc} 
Type of Hernia & \multicolumn{3}{c}{ Side of Hernia } & Total \\
& Right & Left & Bilateral & \\
Direct $(\mathrm{n}, \%)$ & $5(55.6)$ & $1(11.1)$ & $3(33.3)$ & $9(100.0)$ \\
Indirect $(\mathrm{n}, \%)$ & $10(55.6)$ & $8(44.4)$ & $0(.0)$ & $18(100.0)$ \\
Pantaloon $(\mathrm{n}, \%)$ & $1(33.3)$ & $1(33.3)$ & $1(33.3)$ & $3(100.0)$ \\
Total $(\mathbf{n}, \mathbf{\%})$ & $\mathbf{1 6 ( 5 3 . 3 )}$ & $\mathbf{1 0 ( 3 3 . 3 )}$ & $\mathbf{4 ( 1 3 . 3 )}$ & $\mathbf{3 0 ( 1 0 0 . 0 )}$
\end{tabular}

Mean duration of swelling of hernia was $8.90( \pm 3.25)$ years. On an average each operation lasted for 1.18 hours. In this study on an average oral feeding started 12.69 hours after the operation. Average length of postoperative hospital stay was 2.27 days (table III).

\begin{tabular}{|c|c|c|c|c|}
\hline Descriptive statistics & $\begin{array}{l}\text { Minimum } \\
\text { value }\end{array}$ & $\begin{array}{l}\text { Maximum } \\
\text { value }\end{array}$ & Mean & SD \\
\hline Duration of swelling (years) & 5 & 16 & 8.90 & \pm 3.25 \\
\hline Total operation time (hours) & 0.75 & 3.00 & 1.18 & \pm 1.158 \\
\hline Starting of oral feeding (hours) & 6.00 & 48.00 & 12.69 & \pm 11.49 \\
\hline Postoperative hospital stay (day & ys) 1.00 & 4.00 & 2.27 & \pm 0.78 \\
\hline
\end{tabular}

Regarding postoperative complications (10\%) patients developed postoperative urinary retention. Scrotal haematoma formation was observed in 2(6.7\%) cases and local haematoma or seroma formation in incision site was reported in 1 (3.3\%) cases. Scrotal haematoma or seroma and urinary retention both complications coexist in 1 case. In 2 patients $(6.7 \%)$ post operative abdominal distension was found. Using Visual analogue score patients were categorized having mild pain in 13 cases $(43.3 \%)$, moderate pain in 12 cases $(40 \%)$ and severe pain in 5 cases $(16.6 \%)$ after 1st 24 hours of operation (table IV).

Table IV : Postoperative complications

$\begin{array}{lcc}\text { Post operative Complications } & \text { Frequency } & \text { Percent } \\ \text { Postoperative urinary retention } & 3 & 10.0 \\ \text { Scrortalhaematoma formation } & 2 & 6.7 \\ \text { Local haematoma or seroma formation } & 1 & 3.3 \\ \text { Periincisional skin echymosis } & 1 & 3.3 \\ \text { Abdominal distension } & 2 & 6.7 \\ \text { Superficial wound infection } & 1 & 3.3 \\ \text { Pyrexia } & 1 & 3.3\end{array}$

Post Operative Pain in $\mathbf{2 4}$ hours

$\begin{array}{lccc}\text { Mild pain } & 0-30 \mathrm{~mm} & 13 & 43.4 \\ \text { Moderate pain } & 31-60 \mathrm{~mm} & 12 & 40 \\ \text { Severe pain } & 61-90 \mathrm{~mm} & 5 & 16.6 \\ \text { Excruciating pain } & 91-100 \mathrm{~mm} & 0 & 0\end{array}$

Patients were followed up at the end of first week, third month and sixth month after operation. All patients (30) attended the first, second and third follow up (100\%). Within $1^{\text {st }}$ week urinary retention was the main complication, abdominal distension and scrotal haematoma observed in 2(6.7)cases. Wound infection, Urinary retention, Pyrexia, Periincisional skin echymosis were found in 1 (3.3) cases. At third month follow up groin pain was reported in 3 (10.0). No recurrence or mesh rejection or mesh infection was observed over six months follow up. (table V).

Table V : Follow up findings and managements of complications

\begin{tabular}{|c|c|c|c|c|}
\hline Follow-up & Complaints & $\begin{array}{c}n \\
(\%)\end{array}$ & Measures taken & Outcome \\
\hline \multirow{7}{*}{$\begin{array}{l}\text { End of } 1 \text { st week } \\
\text { (within } 1 \text { st week) }\end{array}$} & Wound infection & $1(3.3)$ & Dressing plus Antibiotic & $\begin{array}{l}\text { Wound } \\
\text { healed }\end{array}$ \\
\hline & Urinary retention & $3(10)$ & $\begin{array}{l}\text { In } 2 \text { cases retention was } \\
\text { relieved by conservative } \\
\text { measure and in } 1 \text { cases } \\
\text { catheterization done }\end{array}$ & \\
\hline & Abdominal distension & $2(6.7)$ & Nil per oral regimen. & Resolved \\
\hline & Pyrexia & $1(3.3)$ & Antipyretic. & Resolved \\
\hline & $\begin{array}{l}\text { Periincisional skin } \\
\text { echymosis }\end{array}$ & $1(3.3)$ & Conservatively treated. & Resolved \\
\hline & Scrotal haematoma & $2(6.7)$ & $\begin{array}{l}\text { In } 1 \text { cases wide bore } \\
\text { needle aspiration done and } \\
\text { other } 1 \text { cases are } \\
\text { conservatively treated. }\end{array}$ & Resolved \\
\hline & $\begin{array}{l}\text { Local seroma or } \\
\text { haematoma }\end{array}$ & $1(3.3)$ & $\begin{array}{l}\text { wide bore needle } \\
\text { aspiration done. In } 2 \\
\text { patients(6.7\%) we } \\
\text { prophylactically used } \\
\text { suction drain tube at tissue } \\
\text { plane where mesh was } \\
\text { placed to prevent blood or } \\
\text { seroma accumulation and } \\
\text { that drain tube was } \\
\text { removed } 2^{\text {nd }} \text { or } 3^{\text {rd }} \\
\text { postoperative period }\end{array}$ & Resolved \\
\hline \multirow[t]{3}{*}{ At 3rd month } & Groin pain & $\begin{array}{l}3 \\
(10.0)\end{array}$ & Analgesic. & Resolved \\
\hline & Wound pain & $1(3.3)$ & Analgesic plus Anxiolytic. & Resolved \\
\hline & Discharging sinus & 0 & & \\
\hline At 6th month & No mesh infection, no m & h rejection & no recurrence were found & \\
\hline
\end{tabular}

\section{Discussion}

In the present study age of the patients ranged from 30 years to 78 years, The mean age was 51.93 ( \pm SD 10.12) years and $70 \%$ of the patients were between 40 to 60 years of age, the most active part of ones life where sound repair of hernias and prevention of recurrence is of great importance. $\mathrm{N}$ Khan and $\mathrm{M}$ Masum reported mean age lower than this study. 3,9

Most of the hernia were of indirect type (18/30) followed by direct type (9/30). In direct type more than half were right sided and one third were present in the both sides. In indirect type $55.6 \%$ of the hernias were right sided and the rest were left sided. These findings were quite comparable with the study findings of N Khan, M Masum and A Ahmed. 3,9,10

Although in Lichtenstein series, over $99 \%$ patients were operated on under local anesthesia. In our series all of the cases $(n=30)$ were done under spinal anesthesia. Duration of surgery 
was longer in the complete variety. Therefore scope of local anesthesia was not present. Moreover, ambulatory surgery as day case has not yet been developed and accepted by patients in our setting.

In this study mean duration of swelling of hernia was 8.90 $( \pm 3.25)$ years which was longer duration than other studies ${ }^{11-13}$ of hernia repair by Lichtenstein technique. This might be due to incomplete hernia remain untreated for long period of time and gradually enlarged to complete variety.

In our study 2 patients $(6.7 \%)$ had a prolonged recovery and presented with abdominal distention after operation but settled on a nil per oral regimen. Considering the average length of postoperative hospital stay that was 2.27 days in the present study. It was less than 3 days but little more than other studies of inguinal hernia repair by Lichtenstein technique. ${ }^{5,14}$

Results of the present study took into account the early complications of surgery following the Lichtenstein technique. In this series leading post operative complication was postoperative urinary retention $(10 \%)$ which was higher than other studies of inguinal hernia repair by same technique. ${ }^{11-12}$ In our study scrotal haematoma formation was observed in 2(6.7\%)cases and local haematoma or seroma formation in incision site was reported in 1 (3.3\%) cases that was also higher than other studies of inguinal hernia repair by same technique. ${ }^{15,16}$ Cause may be due to more tissue dissection, large hernial sac exploration and sometimes hernia sac was removed in complete variety where hernia contents were adherent to sac wall.

In 2 patients $(6.7 \%)$ we prophylactically used suction drain tube at tissue plane where mesh were placed to prevent accumulation of blood or seroma and that drain tube was removed $2^{\text {nd }}$ or $3^{\text {rd }}$ postoperative period. Using Visual analogue score patients were categorized having mild pain in 13 cases $(43.4 \%)$, moderate pain in 12 cases $(40 \%)$ and severe pain in 5 cases $(16.6 \%)$ after 1 st 24 hours of operation. This findings were compatible with other studies of inguinal hernia repair by Lichtenstein technique. ${ }^{11-13}$

Periincisional skin echymosis, abdominal distension and superficial wound infection, postoperative pyrexia were the other complications reported. Incidence of these complications in this study was similar to those in other studies. ${ }^{12,16}$

In the current study no case of recurrence was noted within 6 months of follow up period while A Ahmed reported 1\% recurrence rate which was slightly higher than that in the Lichtenstein series but lower than that of Tinckler's series. ${ }^{11}$

\section{Conclusion}

In this study on Lichtenstein tension free mesh repair for complete variety of inguinal hernia within short time post operative follow up period no recurrence or mesh rejection or mesh infection was observed and patient's compliance was good with minimum morbidity. Therefore, it can be said that, Lichtenstein polypropylene mesh repair is safe and reliable method for repair of complete variety inguinal hernia. Long time postoperative follow up is needed for evaluation of mesh related long term complications. Multi-centre studies with larger sample and longer duration and more sound study design could bring more insight regarding this issue.

\section{Limitations of the study}

This study was done in a single centre with a relatively small sample size and observations may be different from the whole country. As duration of study and follow up period was short so long term results of the operative procedure could not be assessed.

\section{Acknowledgement}

The authors would like to express their sincere gratitude to the participants of the study, hospital administration team of HFRCMCH and authors also grateful to Dr. Imtiaz Ahmad, Professor, Surgery department, HFRCMCH, Dr. Nasreen Begum, Assistant Professor, Dept. of community Medicine and Prof. B H Nazma Yasmeen, Professor and Head, Dept. of Paediatrics, Northern International Medical College for their cordial cooperation and advice regarding this article.

\section{References}

1. Bowen JR, Thompson WR, Dorman BA, Soderberg CH, Shahinian TK. Change in the management of adult groin hernia. American Journal of Surgery 1977; 135:564-3.

2. Malik AM, Khan A, Talpur K, Hussain A; Laghari AA. Open mesh repair of different hernias. Is the technique free of complications? BJMP 2009;2(3):38.

3. Khan N, Naeem M, Bangash A, Asadullah, Sadiq M, Hamid H. Early outcome of Lichtenstein technique of tension-free open mesh repair for inguinal hernia. J Ayub Med Coll Abbottabad 2008;20(4):29-33.

4. Millikan K, Cummings B, Doolas A. Prospective study of the mesh plug hernioplasty. Journal of American College of Surgery 2001;67:285-9.

5. Post S, Weiss B, Willer M, Neufang T, Lorenz D. Randomized clinical trial of lightweight composite mesh for Lichtenstein inguinal hernia repair. British Journal of Surgery 2004;91:44-8.

6. Millikan K, Cummings B, Doolas A. Prospective study of the mesh plug hernioplasty. Journal of American College of Surgery 2001;67:285-9.

7. Schumpelick V, Klinge U. The properties and clinical effects of various types of mesh used in hernia repair. Association of Great Britain and Ireland (Yearbook) 2001.

8. Francoisi C, Romano F, Ancaprotti R. Hernia repair with prolene mesh according to Lichtenstein technique results of 692 cases. Minerva Chir 2000; 55.

9. Kingsnoth A. Lichtenstein patch or mesh plug and patch in inguinal hernia. A prospective double randomized controlled trial of short term outcome Surgery. Journal of American College of Surgery 2000;27(3):27.

10. Masum M. Tension free open mesh repair of inguinal hernia - a study of 100 cases.[Dissertation]. Bangabandhu Sheikh Mujib Medical University. Dhaka 2013.

11. Ahmed A. Output of Lichtenstein repair of inguinal hernia in Khulna medical college and hospital, Khulna [dissertation]. Department of Surgery. Khulna Medical College and Hospital, Khulna, Bangladesh. 2012.

12. Prior MJ, Williams EV, Shukla HS, Phillips S, Vig's, Lewis M. Prospective randomized controlled trial comparing Lichtenstein mesh repair with modified Bassini repair of inguinal hernia. Journal of Royal College of Surgery 1998;43:82-6.

13. Mokete M, Earnshaw JJ. Evolution of an inguinal hernia surgery practice. Postgrad MedJ2001;77:188-190.

14. Arnauld JP, Eloy R, Adloff M. Critical evaluation of prosthetic materials in repairs in repair of abdominal hernias. Am J Surg 1984;25:35-44

15. Gai $\mathrm{H}$. The Lichtenstein technique- "minimally invasive surgical procedure." Experiences and results of 251 hernia repairs. Langenbecks Arch ChirSupplKongresbd1996;113:606-8.

16. Sakorafas GH, Halikias I, Nissotakis C, Kotsifopoulos N, Stavrou A \&Kassaras GA et al. Open tension free repair of inguinal hernias; the Lichtenstein technique BMC Surgery 2001;1(3):1471-82. 